\title{
Establishment of normal reference intervals in serum biochemical parameters of domestic sows in Korea
}

\author{
Dongyub Kim ${ }^{1, \#}$, Hwan-Deuk Kim ${ }^{1,2, \#}$, Youngmin Son ${ }^{1}$, Sungho Kim ${ }^{1}$, Min Jang ${ }^{1}$, Seul-Gi Bae ${ }^{1}$, \\ Sung-Ho Yun ${ }^{1}$, Seung-Joon $\mathrm{Kim}^{1}$ and Won-Jae Lee ${ }^{1, *}$ \\ ${ }^{1}$ College of Veterinary Medicine, Kyungpook National University, Daegu 41566, Korea \\ ${ }^{2}$ Department of Veterinary Research, Daegu Metropolitan City Institute of Health \& Environment, Daegu 42183, Korea
}

Received December 10, 2021

Accepted December 14, 2021

\section{*Correspondence \\ Won-Jae Lee \\ E-mail: iamcyshd@knu.ac.kr}

"Both first authors contributed equally to this work.

Author's Position and Orcid no.

Kim DY, PhD candidate,

https://orcid.org/0000-0002-3700-7754

Kim HD, PhD candidate,

https://orcid.org/0000-0003-0917-9863

Son YM, MS student,

https://orcid.org/0000-0002-3387-0526

Kim SH, Student,

https://orcid.org/0000-0001-9088-9840

Jang $\mathrm{M}$, Assistant professor,

https://orcid.org/0000-0002-2188-1906

Bae SG, Assistant professor,

https://orcid.org/0000-0001-9487-5665

Yun SH, Associated professor,

https://orcid.org/0000-0002-9027-3859

Kim SJ, Professor,

https://orcid.org/0000-0002-8521-8898

Lee WJ, Assistant professor,

https://orcid.org/0000-0003-1462-7798

\begin{abstract}
Because sows are industrially vital for swine production, monitoring for their health or disorder status is important to ensure high reproductive performance. Especially, ambient temperature changes in different season, especially during summer, are directly influenced to the reproductive performance of sows. Although the serum biochemical parameters are widely applied in the veterinary medicine with wide ranges for the physiological process, the values are also influenced by several factors such as age, breed, gender, and stress. In addition, domestic sows in Koreaspecific reference interval (RI) for serum biochemistry has not been established yet. Therefore, the present study was aimed to evaluate seasonal variation of RIs in the serum biochemistry in domestic sows in Korea at different seasons and to establish normal Rls using a RI finding program (Reference Value Advisor). Significant difference $(p<0.05)$ on the different seasons were identified in several serum biochemical parameters including BUN, CRE, GGT, GLU, ALB, TP, LDH and Na in sows. Therefore, we further established RIs, specific in domestic sows in Korea regardless of season. The established RIs based on the serum biochemical values provide a baseline for interpreting biochemical results in the domestic sows in Korea, regardless of seasonal effect. It may contribute to develop a strategy for better reproductive performance by improving breeding management practice and evaluating health of pig herds, which facilitate to avert the economic loss in summer infertility in sows.
\end{abstract}

Keywords: domestic sow, reference interval, seasonal variation, serum biochemistry

\section{INTRODUCTION}

Pigs (sus scrofa) are one of the most economically important livestock in the animal industry and important models in the field of the toxicology, preclinical study, and biotechnology due to strong similarities with the human (Ventrella et al., 2016; Choi et al., 2020; Han et al., 2020). As the animal industry in Korea, it is aggregated that the total number of $10,513,803$ pigs has been raised in 4,406 domestic pig farms in Korea at the end of 2017 (available at https://kosis.kr). Because management of sows is the key for better reproductive performance of pig herd, an accurate knowledge of their physiology and health status are highly associated with economic benefit (Ventrella et al., 2016; Hwangbo et al., 2019; Ma et al., 2020). However, several factors and problems such as im- 
balanced nutrition, stress, infectious disease, and housing condition are directly or indirectly influenced to the reproductive performance of sows (Hwangbo et al., 2019; Ma et al., 2020). Of note, their physiological feature, a thick subcutaneous fat and small number of sweat glands, make their reproductive performance reduced especially on summer due to high ambient temperature; it has been known as the summer infertility (Love et al., 1993). Thus, establishment of basic information or wide reference for their physiology depending on different seasons is essential to develop a strategy for better reproductive performance of pig herd.

The serum biochemistry is a well-established laboratory method in the veterinary medicine, plays a pivotal role in assessing animal health and has been regarded as good indicators of the physiological status because it can serve the clinical data for the diagnosis, prognosis, and treatment of livestock diseases with wide ranges for the physiological process including serum proteins, enzymes, hormones, and electrolytes at any given time (Adenkola et al., 2009; Onasanya et al., 2015). However, it has been continuously reported that the serum biochemical values are dependent on environmental and physiologic conditions such as age, gender, feed, additives, stress, and ambient temperature in pigs (Elbers et al., 1992; Dubreuill et al., 1993). For instance, adult wild boars had higher level of total protein (TP), albumin (ALB), creatinine (CRE), and $\mathrm{Cl}$ than juveniles (Casas-Díaz et al., 2015), and the concentrations of TP, ALB and gamma globulin were reduced at sows at weaning relative to $4-5$ weeks gestation (Elbers et al., 1994). In addition, additives such as ascorbic acid, synbiotic (a compound of probiotics and prebiotics), and irons to pigs could alter several values in the serum chemistry (Adenkola et al., 2009; Ventrella et al., 2016; Ma et al., 2020). Furthermore, different levels of blood urea nitrogen (BUN) and TP between other pig breeds were identified (Choi et al., 2021). Especially, since farm pigs in the pigsty cannot well cope with environmental changes by themselves and have difficulty in dissipating excessive heat load in summer due to the aforementioned physiological feature, several previous articles have reported the changed values of serum biochemistry such as serum protein and electrolytes, depending on variable ambient temperature at different seasons (Chmielowiec-Korzeniowska et al., 2012; Mayengbam and Tolenkhomba, 2015).

Because sows are industrially vital for swine production, their monitoring for health or disorder status is important to ensure high reproductive performance and may maximize output of livestock products. Therefore, it is extremely important to have specific reference interval (RI) on serum biochemistry to monitor health status of sows. By accumulated data, the normal RIs in the serum biochemical values which can cover general pig herds are readily available in several articles and routinely served by the manufacturer of serum chemistry machine. Unfortunately, although the serum biochemical values can be affected by different seasons, breeds, and gender, the normal RIs that are specific in the domestic sows in Korea are still not available yet; the inappropriate RIs during serum biochemistry are possibly resulted in wrong clinical interpretation to the animal. Therefore, the present study was aimed to evaluate seasonal variation of RIs in the serum biochemistry in domestic sows in Korea at different seasons and to establish normal RIs using a RI finding program (Reference Value Advisor) for the veterinary clinicians and the relevant researchers.

\section{MATERIALS AND METHODS}

\section{Ethics statement}

All procedures for sampling animal specimens were approved by the Institutional Animal Care Use Committee at Kyungpook National University (approval number: 20210098).

\section{Acquisition of serum samples from domestic sows}

Samples from healthy sows (total $n=48$ ) were only collected with examination by 2 veterinarians, following the basic physical examinations by checking normality in body condition, appetite, and lymph nodes, and absence of external wound and diarrhea. In addition, the health status with no infectious disease was additionally confirmed by checking dressed carcass of sows after slaughtering. The sows (three-way crossbred by Landrace $\times$ Yorkshire $\times$ Duroc, LYD; approximately 2 -year-old; approximately $200 \mathrm{~kg}$ body weight; non-pregnant; experienced birth 3-5 times; fed for fully balanced commercial feeds and accessed to water ad libitum) from 5 domestic pig farms, located near Daegu-si (latitude: $128.63^{\circ} \mathrm{E}$; longitude: $35.87^{\circ} \mathrm{N}$ ), republic of Korea. The sampling was conducted in different seasons in regards with spring (SP; $n=16$; maximal ambient temperature: $17-22^{\circ} \mathrm{C}$ ), summer 
( $\mathrm{S} ; \mathrm{n}=16$; maximal ambient temperature: $\left.32-36^{\circ} \mathrm{C}\right)$, and fall/winter $(\mathrm{F} / \mathrm{W} ; \mathrm{n}=16$; maximal ambient temperature: $3-8^{\circ} \mathrm{C}$ ). During slaughtering at the local abattoir, fresh whole bloods via jugular venipuncture were collected in the plain tubes and allowed to clot at room temperature. Thereafter, sera were isolated by centrifugation at 4,000 rpm for $15 \mathrm{~min}$ in $4^{\circ} \mathrm{C}$. The isolated sera were subsequently transferred into new tubes and stored in aliquots at a deep freezer at $-80^{\circ} \mathrm{C}$ until further analysis. Measurement of serum biochemistry analytes was performed on the DRI CHEM NX500i (Fujifilm, Tokyo, Japan) with respect to BUN, CRE, GGT, ALB, TP, TG, TCHO, alkaline phosphatase (ALP), glutamic pyruvic transaminase (GPT; also known as alanine aminotransferase, ALT), glutamic oxaloacetic transaminase (GOT; also known as aspartate aminotransferase, AST), glucose (GLU), lipase (vLIP), lactate dehydrogenase (LDH), inorganic phosphorus (IP), $\mathrm{Ca}, \mathrm{Na}$, $\mathrm{K}$, and $\mathrm{Cl}$; in general, the serum biochemical parameters indicated as follows: BUN, CRE, and GOT for changed functions of the skeletal or cardiac muscle; BUN, GLU ALP, ALB, TP, and AST for dysregulation of the liver; TP, ALB, CRE, BUN, $\mathrm{Ca}$, and IP for the kidney function; GLU, TG, and TCHO on energy balance; $\mathrm{Na}, \mathrm{K}, \mathrm{Cl}$, and TP into function of the metabolic and digestive system (Rymut et al., 2021).

\section{Analysis for descriptive statistics and reference intervals (RIs) in serum biochemistry}

In the analysis for descriptive statistics, the raw values in each parameter of serum biochemistry in sows were calculated for the mean and standard deviation (SD), thereafter, the significant differences $(p<0.05)$ depending on different seasons were assessed by SPSS with Duncan`s post hoc (SPSS 12.0, SPSS Inc. Chicago, IL, USA); the results were presented as mean $\pm \mathrm{SD}$. The Reference Value Advisor, a set of macroinstructions for Microsoft Excel (Microsoft, Redmond, WA, USA), was applied to calculate RIs using each serum biochemical value, in accordance with developer's article (Geffré et al., 2011). In brief, the values were assessed for Gaussian (normality) and symmetry distribution by Anderson-Darling test, and outliers were presented after Turkey's test. In accordance with the developer's suggestion, extreme outliers with aberrant values among several outliers were only eliminated until ensuring Gaussian and symmetry distribution for proper computations. Then the data were analyzed by a non- parametric method when the sample size is large enough ( $n \geq 40$ ) or a robust method with Box-Cox transformation in case of small sample size $(n<40)$; because the number of samples in the present study was more than $40(n=48)$, the former analysis was conducted. Then Reference Value Advisor calculated RIs for each parameter with $90 \%$ confidence intervals (CI).

\section{RESULTS}

\section{Analysis for descriptive statistics in serum biochemistry}

The eighteen serum biochemical parameters in domestic sows in Korea were analyzed for descriptive statistics and presented fluctuating values depending on sampled seasons (Table 1). Significant difference $(p<0.05)$ on the different seasons were identified in several parameters including BUN, CRE, GGT, GLU, ALB, TP, LDH and Na. In detail, CRE was elevated but GLU and ALB were decreased in summer than spring. In addition, GGT and LDH were increased in fall/winter than spring. Interestingly, several values including ALP, GOT, GGT, ALB, and LDH were determined as unduly out of range of upper and lower limits served by manufacturer of serum chemistry machine. Therefore, we further investigated to establish domestic sows in Korea-specific RIs regardless of season.

\section{Establishment of Rls in domestic sows in Korea}

Fig. 1 represented the box and whiskers diagram (median, 25th and 75th percentiles, and $95 \%$ CI of mean) with dot plots of values and mild outliers (red X), after eliminating extreme outliers. Based these distribution, Reference Value Advisor calculated fitted distribution (fink curves), followed by presenting upper and lower RIs (blue lines) with 90\% CI (dotted boxes) (Fig. 2). The obtained values for RIs with CIs were digitized in Table 2. All values were identified as Gaussian and symmetrical after eliminating extreme outliers $(p>0.05)$. Finally, new RIs were established, based on descriptive statistics in serum biochemistry in Table 1. In detail, compared with the limit values in Table 1, the range of upper and lower limits were enlarged in GLU and TCHO or reduced in BUN. In addition, both upper and lower limits were increased in CRE, ALP, GOT, ALB, TP, and LDH. And only upper limit was increased in GPT and GGT. Because the sows in the present study were determined as health status with 
J Anim Reprod Biotechnol Vol. 36, No. 4, December 2021

Table 1. The values of serum biochemistry of domestic sows in Korea

\begin{tabular}{|c|c|c|c|c|c|c|}
\hline \multirow{2}{*}{ Parameter } & \multirow{2}{*}{ Units } & \multicolumn{3}{|c|}{ Descriptive statistics on different seasons } & \multicolumn{2}{|c|}{ DRI CHEM NX500i } \\
\hline & & SP & $\mathrm{S}$ & F/W & Lower limit & Upper limit \\
\hline BUN & $\mathrm{mg} / \mathrm{dL}$ & $14.36 \pm 0.67^{\mathrm{ab}}$ & $12.93 \pm 0.82^{\mathrm{a}}$ & $15.85 \pm 0.96^{b}$ & 8.2 & 25.0 \\
\hline CRE & $\mathrm{mg} / \mathrm{dL}$ & $1.80 \pm 0.07^{\mathrm{a}}$ & $2.44 \pm 0.08^{b}$ & $1.92 \pm 0.09^{\mathrm{a}}$ & 0.8 & 2.3 \\
\hline ALP & $U / L$ & $156.62 \pm 15.79$ & $163.80 \pm 31.14$ & $185.60 \pm 29.27$ & 41.0 & 176.0 \\
\hline GPT & $U / L$ & $45.43 \pm 1.81$ & $47.60 \pm 7.45$ & $48.46 \pm 3.75$ & 22.0 & 47.0 \\
\hline GOT & $U / L$ & $65.75 \pm 4.87$ & $101.37 \pm 26.38$ & $149.86 \pm 50.11$ & 15.0 & 55.0 \\
\hline GGT & $U / L$ & $56.93 \pm 7.94^{\mathrm{a}}$ & $51.87 \pm 5.73^{\mathrm{a}}$ & $79.86 \pm 6.84^{b}$ & 31.0 & 52.0 \\
\hline GLU & $\mathrm{mg} / \mathrm{dL}$ & $105.50 \pm 4.03^{\mathrm{a}}$ & $79.93 \pm 3.42^{b}$ & $109.60 \pm 3.76^{a}$ & 66.0 & 116.0 \\
\hline ALB & $\mathrm{g} / \mathrm{dL}$ & $5.15 \pm 0.11^{\mathrm{a}}$ & $4.78 \pm 0.13^{b}$ & $5.14 \pm 0.09^{\mathrm{a}}$ & 2.3 & 4.0 \\
\hline $\mathrm{TP}$ & $\mathrm{g} / \mathrm{dL}$ & $8.76 \pm 0.19^{\mathrm{ab}}$ & $8.42 \pm 0.18^{a}$ & $9.22 \pm 0.13^{b}$ & 5.8 & 8.3 \\
\hline TG & $\mathrm{mg} / \mathrm{dL}$ & $58.62 \pm 5.23$ & $73.81 \pm 9.94$ & $73.73 \pm 11.80$ & - & - \\
\hline $\mathrm{TCHO}$ & $\mathrm{mg} / \mathrm{dL}$ & $98.18 \pm 4.34$ & $103.06 \pm 9.20$ & $108.00 \pm 7.38$ & 81.0 & 134.0 \\
\hline vLIP & $U / L$ & $34.31 \pm 1.10$ & $35.00 \pm 2.33$ & $35.20 \pm 0.84$ & - & - \\
\hline $\mathrm{LDH}$ & $U / L$ & $559.12 \pm 43.96^{a}$ & $551.87 \pm 41.04^{a}$ & $712.73 \pm 50.27^{b}$ & 160.0 & 425.0 \\
\hline IP & $\mathrm{mg} / \mathrm{dL}$ & $7.74 \pm 0.26$ & $7.86 \pm 0.28$ & $8.56 \pm 0.28$ & 5.5 & 9.3 \\
\hline $\mathrm{Ca}$ & $\mathrm{mg} / \mathrm{dL}$ & $10.83 \pm 0.13$ & $10.76 \pm 0.12$ & $11.28 \pm 0.27$ & 9.3 & 11.5 \\
\hline $\mathrm{Na}$ & $\mathrm{mEq} / \mathrm{L}$ & $148.56 \pm 0.86^{\mathrm{ab}}$ & $147.43 \pm 1.00^{\mathrm{a}}$ & $150.40 \pm 0.74^{b}$ & 139.0 & 153.0 \\
\hline K & $\mathrm{mEq} / \mathrm{L}$ & $5.98 \pm 0.31$ & $5.78 \pm 0.21$ & $5.89 \pm 0.21$ & 4.4 & 6.5 \\
\hline $\mathrm{Cl}$ & $\mathrm{mEq} / \mathrm{L}$ & 102.310 .57 & $101.50 \pm 0.94$ & $103.53 \pm 0.79$ & 97.0 & 106.0 \\
\hline
\end{tabular}

$\mathrm{SP}, \mathrm{S}$ or F/W indicates the sows during spring, summer or fall/winter, respectively. The values at the columns of Descriptive statistics on different seasons are displayed as means \pm SD and significant differences are presented as different alphabet letters $(p<0.05)$. The values at the columns of DRI CHEM are normal ranges in pigs of each parameter, suggested from the manufacturer.



Fig. 1. Distribution of serum biochemical values in each parameter. The distribution of serum biochemical values in each parameter is presented as the box and whiskers diagrams (median, 25th and 75th percentiles, and $95 \% \mathrm{Cl}$ of mean) with dot plots of values. Mild outliers were expressed as the red Xs.

enough number for statistical analysis, and aberrant outliers were eliminated, the established RIs were believed as reliable results, specific in domestic sows in Korea.

\section{DISCUSSION}

Since pigs are probably one of the most important animals in several fields, a complete and accurate understanding for their physiology is mandatory (Ventrella et al., 2016). Through several articles, it has been noted that 
serum biochemical values or RIs are affected by various factors such as age, stress, diet, geography, season, gender, husbandry, and breed (Yeom et al., 2012; Casas-Díaz et al., 2015; Yu et al., 2019). Especially, the physiological signs of heat stress in pigs contain the elevation of respiration rate, body temperature, pulse rate, and panting as well as reduction in feed intake, followed by decreased reproductive performance; alterations of several serum biochemical values have been also presented from various articles in pigs under high ambient temperature (Pearce et al., 2013; Mayengbam and Tolenkhomba, 2015). However, the serum biochemical values depending on dif-


Observed distribution - Fitted distribution - Reference limits - - $90 \% \mathrm{Cl}$

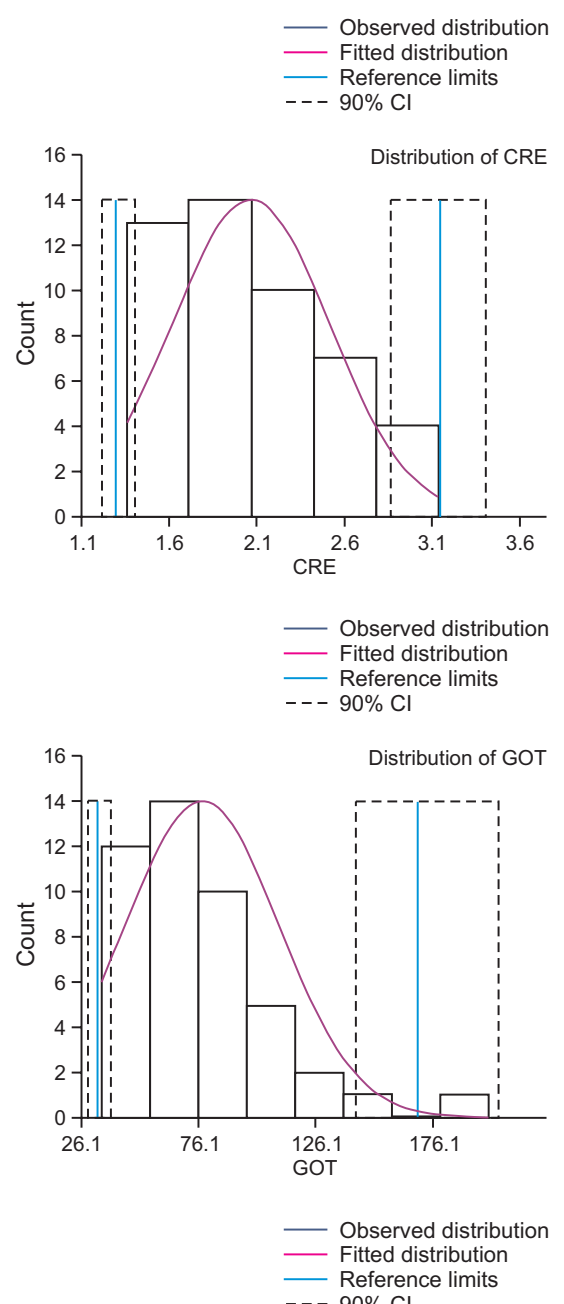
- - $90 \% \mathrm{Cl}$



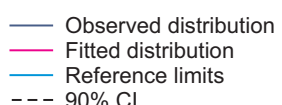


- Observed distribution - Fitted distribution - Reference limits - - - $90 \%$ C

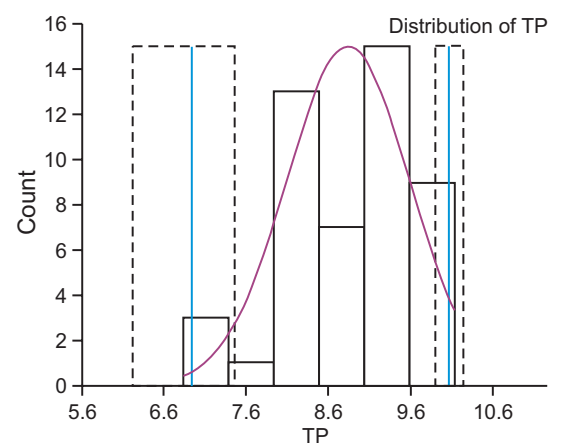

Fig. 2. Calculation of reference intervals (RIs) using Reference Value Advisor in serum biochemical values of each parameter. Fitted distribution or upper/lower RIs or $90 \% \mathrm{Cl}$ is presented as fink curve or blue line or dotted boxes, respectively. 

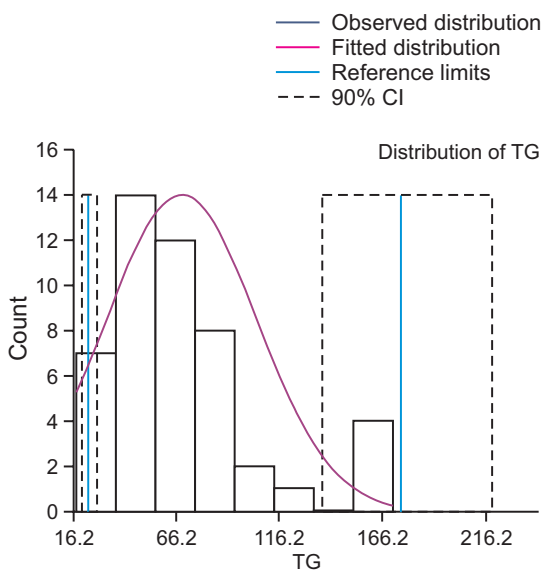

- Observed distribution - Fitted distribution - - $90 \% \mathrm{Cl}$
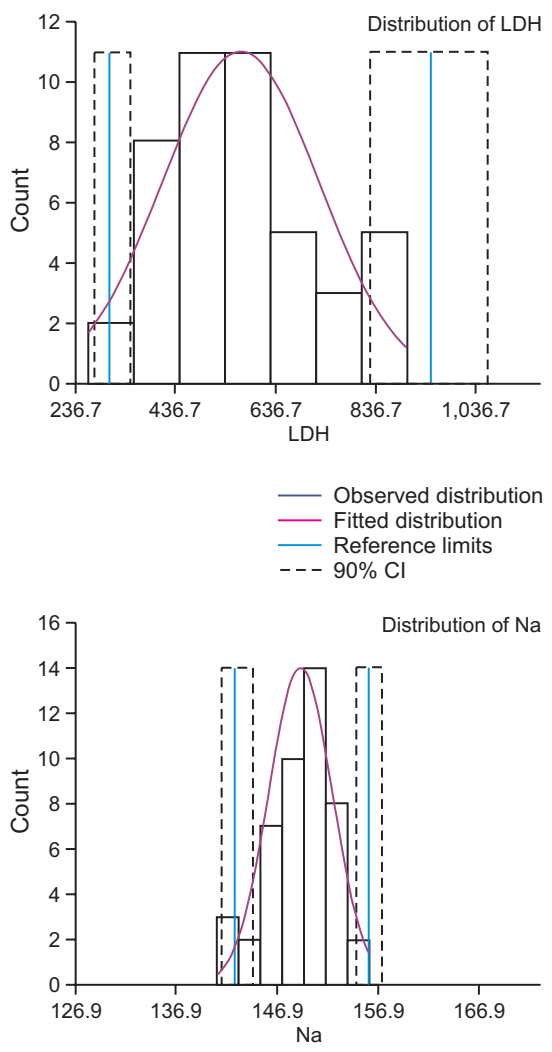

- Observed distribution

- Fitted distribution

- Reference limits

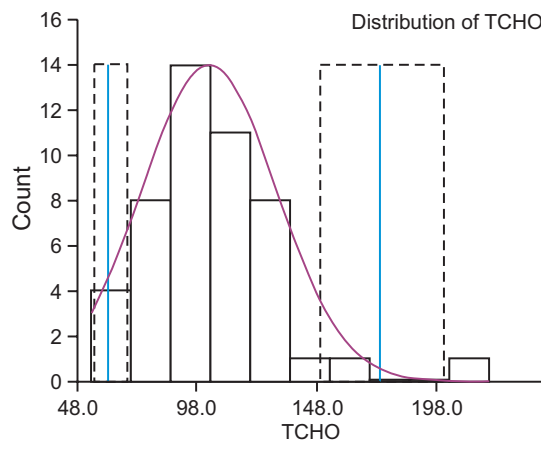

- Observed distribution - Fitted distribution Reference limits

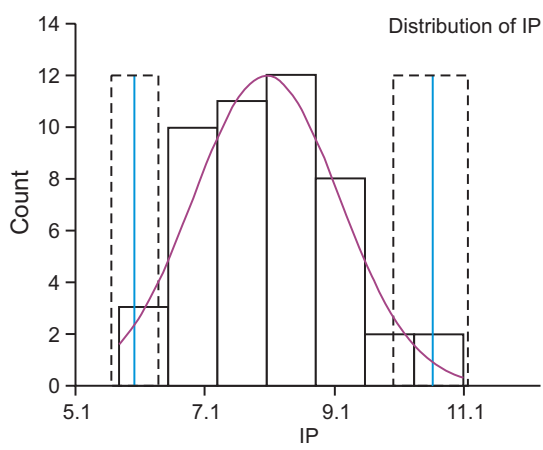

- Observed distribution — Fitted distribution - Reference limits - - $90 \% \mathrm{Cl}$

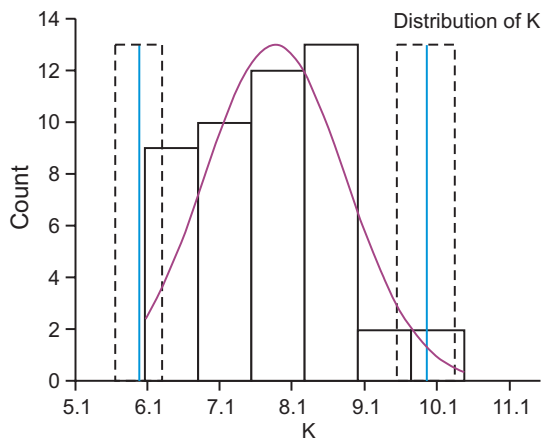

- Observed distribution

— Fitted distribution Reference limits $---90 \% \mathrm{Cl}$

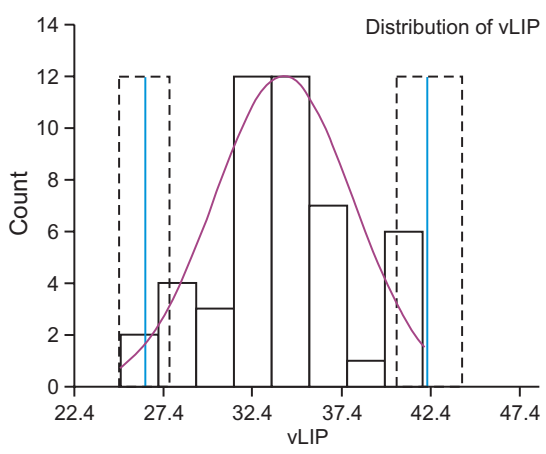

- Observed distribution - Fitted distribution - Reference limits - - $90 \% \mathrm{Cl}$

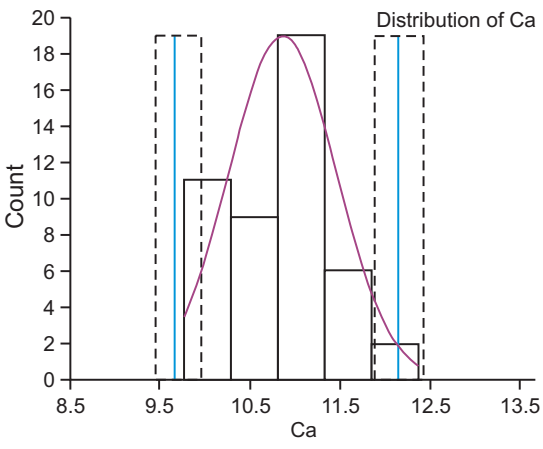

- Observed distribution - Fitted distribution - Reference limits - - $90 \% \mathrm{Cl}$



Fig. 2. Continued.

ferent seasons including summer and its RIs were poorly understood in domestic sows in Korea. Therefore, we established domestic sows in Korea-specific RIs regardless of season, which was calculated from serum biochemical values of healthy subjects. These RIs can possibly be a parameter for sow herd health control, especially in summer infertility, because it reflects the health status of the herd.

As aforementioned, it has been addressed that serum biochemical values and RIs of pigs are affected by external factors, especially on heat stress. In the biochemical analysis of pigs fattened in summer and winter, summer group presented a higher content of TP, TCHO, TG, GGT, and GOT (Chmielowiec-Korzeniowska et al., 2012). When 
Kim et al. Serum biochemical RIs in domestic sows

Table 2. Biochemical reference intervals (RI) of domestic sows in Korea

\begin{tabular}{|c|c|c|c|c|c|c|}
\hline \multirow[b]{2}{*}{ Para-meter } & \multirow[b]{2}{*}{ Units } & \multicolumn{3}{|c|}{ Anderson-Darling test } & \multicolumn{2}{|c|}{ RI with $90 \%$ confidence interval } \\
\hline & & $\#$ & $\begin{array}{c}\text { Gaussian } \\
\text { distribution }\end{array}$ & $\begin{array}{l}\text { Symmetry } \\
\text { distribution }\end{array}$ & Lower limit $(\mathrm{Cl})$ & Upper limit (Cl) \\
\hline BUN & $\mathrm{mg} / \mathrm{dL}$ & 48 & 0.546 & 0.191 & $9.64(9.60-9.99)$ & $21.64(20.65-21.80)$ \\
\hline CRE & $\mathrm{mg} / \mathrm{dL}$ & 48 & 0.765 & 0.809 & $1.38(1.37-1.47)$ & $3.12(2.91-3.14)$ \\
\hline ALP & $U / L$ & 44 & 0.121 & 0.620 & $78.38(78.00-85.50)$ & $292.50(220.08-297.00)$ \\
\hline GPT & $U / L$ & 46 & 0.714 & 0.276 & $28.53(28.00-32.00)$ & $71.48(56.65-72.00)$ \\
\hline GOT & $U / L$ & 45 & 0.730 & 0.326 & $35.45(35.00-39.15)$ & $192.48(123.35-200.00)$ \\
\hline GGT & $U / L$ & 48 & 0.913 & 0.500 & $22.00(22.00-24.13)$ & $142.38(113.04-148.00)$ \\
\hline GLU & $\mathrm{mg} / \mathrm{dL}$ & 48 & 0.529 & 0.191 & $62.23(62.00-64.68)$ & $142.53(130.96-145.00)$ \\
\hline ALB & $\mathrm{g} / \mathrm{dL}$ & 48 & 0.339 & 0.215 & $3.82(3.80-4.20)$ & $5.77(5.60-5.80)$ \\
\hline TP & $\mathrm{g} / \mathrm{dL}$ & 48 & 0.141 & 0.113 & $6.87(6.80-7.38)$ & $10.01(9.68-10.10)$ \\
\hline $\mathrm{TG}$ & $\mathrm{mg} / \mathrm{dL}$ & 48 & 0.574 & 0.385 & $20.03(18.00-29.00)$ & $168.98(151.43-171.00)$ \\
\hline $\mathrm{TCHO}$ & $\mathrm{mg} / \mathrm{dL}$ & 48 & 0.538 & 0.280 & $55.80(54.0-66.0)$ & $207.20(138.1-220.0)$ \\
\hline VLIP & $U / L$ & 47 & 0.140 & 0.098 & $25.40(25.00-28.20)$ & $42.00(41.00-42.00)$ \\
\hline $\mathrm{LDH}$ & $U / L$ & 45 & 0.631 & 0.854 & $274.10(263.00-388.45)$ & 899.85 (878.70-900.00) \\
\hline $\mathbb{I P}$ & $\mathrm{mg} / \mathrm{dL}$ & 48 & 0.796 & 0.500 & $5.85(5.80-6.36)$ & $10.97(9.97-11.10)$ \\
\hline $\mathrm{Ca}$ & $\mathrm{mg} / \mathrm{dL}$ & 47 & 0.187 & 0.101 & $9.82(9.800-10.02)$ & $12.36(11.58-12.40)$ \\
\hline $\mathrm{Na}$ & $\mathrm{mEq} / \mathrm{L}$ & 48 & 0.223 & 0.105 & $141.18(141.00-144.93)$ & $155.83(153.00-156.00)$ \\
\hline K & $\mathrm{mEq} / \mathrm{L}$ & 48 & 0.796 & 0.615 & $4.12(4.10-4.42)$ & $6.34(6.23-6.50)$ \\
\hline $\mathrm{Cl}$ & $\mathrm{mEq} / \mathrm{L}$ & 46 & 0.171 & 0.058 & $97.30(97.00-99.15)$ & $107.85(106.85-108.00)$ \\
\hline
\end{tabular}

\# indicates the number of sows applied in assessment by Reference Value Advisor, after eliminating the subject (s) who shows the extreme outlier; the number of eliminated outliers is able to be speculated by a numerical difference with 48. Gaussian (normality) and symmetry distribution are evaluated by Anderson-Darling test. RI indicates the reference interval of lower or upper limit with $90 \%$ confidence interval (Cl) and is automatically computed by a nonparametric reference statistical test programmed in Reference Value Advisor.

the influence of season (summer and winter) on enzyme and electrolyte parameters in the serum was investigated at a different age, GOT was increased during summer in both the grower and adult pigs, and increase of $\mathrm{Na}$, $\mathrm{K}$, $\mathrm{Ca}$, and $\mathrm{Mg}$ was observed in pre-weaning piglets and grower pigs in summer than winter (Mayengbam and Tolenkhomba, 2015).

Furthermore, the effect of other types of stressors (e.g. weaning stress and infection) on serum biochemical values and RIs in pigs has been investigated. A study was conducted to establish the influence of weaning on RIs of serum biochemistry for piglets and resulted that TCHO and TG were elevated at 0 days post-weaning, compared with other post-weaning duration (Yu et al., 2019). In the study with weaned piglets with/without infection of porcine reproductive and respiratory syndrome virus and with/without nursery, there were significant difference in the anion gap, BUN and TG (Rymut et al., 2021). When the serum biochemistry between pigs with/without restraint, increases of TP and electrolytes were found in stressed animals and it was returned within 30 min after cessation of stress (Dubreuill et al., 1993). Other external factors in terms of additives, ages, and breeds are necessary to consider when the serum biochemical values are interpreted. Transportation-stressed pigs presented higher TP, ALP, and GOT than ascorbic acid-supplemented pigs (Adenkola et al., 2009). Because the dietary synbiotic supplementation in pregnant and lactating pigs induced an increase of TG, TCHO, GLU, and ALP, it would be helpful for pregnant sows to support the growth and development of their fetuses (Ma et al., 2020). In addition, breedsdependent difference in serum biochemistry was found between native pig (Woori black pig) and LYD with showing lower TP and BUN level but higher GLU in LYD (Choi et al., 2021). Furthermore, the values of TP and ALB in the serum were lower in sows at weaning than at 4-5 weeks gestation (Elbers et al., 1994). And age-related serum biochemical changes were identified as BUN, $\mathrm{K}, \mathrm{Ca}$, and IP were higher in younger pigs than juvenile pigs (Yeom et al., 2012). Likewise, these accumulated data comprehensively explain that several factors including heat on summer are enough to change the serum biochemical values, 
even in healthy pigs.

In the descriptive statistics in Table 1 , several values were changed depending on different seasons. Because the sows in the present study were healthy on physical examinations and free to infectious disease when checking dressed carcass, it could be concluded that some external factors influenced to the serum biochemical values. Additional clinical diagnosis was further required, but the increase of CRE during summer in sows was speculated due to fluid loss in the body via decrease of urine volume during increase of evaporation on summer (Yokus et al., 2006; Onasanya et al., 2015). Elevation of ALB and TP levels in all groups could be explained as dehydration during transportation to the abattoir. The increase of liver parameters including ALP, GPT and GOT during winter was thought to be caused by changed feed quality or natural seasonal variations (Miyake et al., 2009; Aguirre et al., 2018).

\section{CONCLUSION}

Specific information about RIs depending on certain external factors for healthy animals is an essential step for the adequate management of herd. Therefore, the present study was conducted in order to investigate seasonal variation on serum biochemical parameters. The established RIs based on the serum biochemical values provide a baseline for interpreting biochemical results in the domestic sows in Korea, regardless of seasonal effect. It may contribute to develop a strategy for better reproductive performance by improving breeding management practice and evaluating health status of pig herds, which facilitate to avert the economic loss in summer infertility of sows.

Author Contributions: Conceptualization, D.Y.K., H.D.K., and W.J.L.; data curation, D.Y.K. and H.D.K.; formal analysis, D.Y.K., H.D.K., and W.J.L.; funding acquisition, W.J.L.; investigation, D.Y.K., H.D.K., Y.M.S. and S.H.K.; methodology, D.Y.K., H.D.K., Y.M.S. and S.H.K.; project administration, W.J.L.; resources, D.Y.K. and H.D.K.; software, D.Y.K. and H.D.K.; supervision, M.J., S.G.B. and S.H.Y.; validation, M.J., S.G.B. and S.H.Y.; visualization, D.Y.K. and H.D.K.; writing-original draft preparation, D.Y.K. and H.D.K.; writing-review and editing, S.J.K., W.J.L.
Funding: This work was supported by a grant from the National Research Foundation (NRF) of Korea, funded by the government of the Republic of Korea (NRF2020R1F1A1076723).

Ethical Approval: All procedures for sampling animal specimens were approved by the Institutional Animal Care Use Committee at Kyungpook National University (approval number: 2021-0098).

Consent to Participate: Not applicable.

Consent to Publish: Not applicable.

Availability of Data and Materials: The data used to support the findings of this study are available from the corresponding author upon request.

Acknowledgements: We thanks to the financial support of NRF.

Conflicts of Interest: No potential conflict of interest relevant to this article was reported.

\section{REFERENCES}

Adenkola AY, Ayo JO, Sackey AKB, Adelaiye AB. 2009. Haematological and serum biochemical changes in pigs administered with ascorbic acid and transported by road for four hours during the harmattan season. J. Cell Anim. Biol. 3:2128.

Aguirre EL, Quezada M, Uchuari M, Mamani G. 2018. ALP-AST/ GOT-ALT/GPT-Bilirubin in serum from Bos Taurus cows in the postpartum period and maintained by grazing in the humid tropic region. ARC J. Anim. Vet. Sci. 4:20-25.

Casas-Díaz E, Closa-Sebastià F, Marco I, Lavín S, Bach-Raich E, Cuenca R. 2015. Hematologic and biochemical reference intervals for Wild Boar (Sus scrofa) captured by cage trap. Vet. Clin. Pathol. 44:215-222.

Chmielowiec-Korzeniowska A, Tymczyna L, Babicz M. 2012. Assessment of selected parameters of biochemistry, hematology, immunology and production of pigs fattened in different seasons. Arch. Tierz. 55:469-479.

Choi KH, Lee DK, Oh JN, Kim SH, Lee M, Jeong J, Choe GC, Lee CK. 2020. Generation of neural progenitor cells from pig embryonic germ cells. J. Anim. Reprod. Biotechnol. 35:4249.

Choi YH, Jeong YD, Cho ES, Kim YH, Kim JE, Jung HJ, Jin HJ, Min YJ. 2021. Comparison of blood characteristics between 
Woori black pig and crossbred pig at different growth stages: Proceedings of the Korea Academia-Industrial cooperation Society Spring Conference. Cheonan: KAIS. 22, 1026-1028.

Dubreuill P, Farmer C, Couturel Y, Petitclerc D. 1993. Hematological and biochemical changes following an acute stress in control and somatostatin-immunized pigs. Can. J. Anim. Sci. 73:241-252.

Elbers AR, Counotte GH, Tielen MJ. 1992. Haematological and clinicochemical blood profiles in slaughter pigs. Vet. Q. 14:57-62

Elbers AR, Geudeke MJ, van Rossem H, Kroon MC, Counotte GH. 1994. Haematology and biochemistry reference values for sows kept under modern management conditions. Vet. Q. 16:127-130.

Geffré A, Concordet D, Braun JP, Trumel C. 2011. Reference Value Advisor: a new freeware set of macroinstructions to calculate reference intervals with Microsoft Excel. Vet. Clin. Pathol. 40:107-112.

Han NR, Baek S, Lee Y, Lee J, Yun JI, Lee E, Lee ST. 2020. Effects of in vitro culture period of reconstructed embryos and genetic background of feeder cells on establishment of embryonic stem cells derived from somatic cell nuclear transfer blastocysts in pigs. J. Anim. Reprod. Biotechnol. 35:86-93.

Hwangbo Y, Cheong HT, Park CK. 2019. Changes of plasminogen activator activity under heat stress condition in porcine endometrium. J. Anim. Reprod. Biotechnol. 34:240-246.

Love RJ, Evans G, Klupiec C. 1993. Seasonal effects on fertility in gilts and sows. J. Reprod. Fertil. Suppl. 48:191-206.

Ma C, Zhang W, Gao Q, Zhu Q, Song M, Ding H, Yin Y, Kong X. 2020. Dietary synbiotic alters plasma biochemical parameters and fecal microbiota and metabolites in sows. J. Funct. Foods 75:104221.

Mayengbam P and Tolenkhomba TC. 2015. Seasonal variation of hemato-biochemical parameters in indigenous pig:
Zovawk of Mizoram. Vet. World 8:732-737.

Miyake K, Miyake N, Kondo S, Tabe Y, Ohsaka A, Miida T. 2009. Seasonal variation in liver function tests: a time-series analysis of outpatient data. Ann. Clin. Biochem. 46:377-384.

Onasanya GO, Oke FO, Sanni TM, Muhammad AI. 2015. Parameters influencing haematological, serum and bio-chemical references in livestock animals under different management systems. Open J. Vet. Med. 5:181-189.

Pearce SC, Mani V, Weber TE, Rhoads RP, Patience JF, Baumgard LH, Gabler NK. 2013. Heat stress and reduced plane of nutrition decreases intestinal integrity and function in pigs. J. Anim. Sci. 91:5183-5193.

Rymut HE, Rund LA, Bolt CR, Villamil MB, Southey BR, Johnson RW, Rodriguez-Zas SL. 2021. The combined effect of weaning stress and immune activation during pig gestation on serum cytokine and analyte concentrations. Animals (Basel) 11:2274.

Ventrella D, Dondi F, Barone F, Serafini F, Elmi A, Giunti M, Romagnoli N, Forni M, Bacci ML. 2016. The biomedical piglet: establishing reference intervals for haematology and clinical chemistry parameters of two age groups with and without iron supplementation. BMC Vet. Res. 13:23.

Yeom SC, Cho SY, Park CG, Lee WJ. 2012. Analysis of reference interval and age-related changes in serum biochemistry and hematology in the specific pathogen free miniature pig. Lab. Anim. Res. 28:245-253.

Yokus B, Cakir DU, Kanay Z, Gulten T, Uysal E. 2006. Effects of seasonal and physiological variations on the serum chemistry, vitamins and thyroid hormone concentrations in sheep. J. Vet. Med. A Physiol. Pathol. Clin. Med. 53:271-276.

Yu K, Canalias F, Solà-Oriol D, Arroyo L, Pato R, Saco Y, Terré M, Bassols A. 2019. Age-related serum biochemical reference intervals established for unweaned calves and piglets in the post-weaning period. Front. Vet. Sci. 6:123. 